\title{
Hereford-sonnien käyttäytyminen erilaisissa kasvatusympäristöissä
}

\author{
Leena Tuomisto $^{1)}$, Arto Huuskonen ${ }^{1)}$, Jaakko Mononen ${ }^{2)}$, Risto Kauppinen ${ }^{3)}$ ja Sami Huttu ${ }^{1)}$ \\ ${ }^{1)}$ MTT / Pohjois-Pohjanmaan tutkimusasema,92400 Ruukki, etunimi.sukunimi@mtt.fi \\ ${ }^{2)}$ Kuopion yliopisto, Soveltavan biotekniikan instituutti, PL 1627, 70211 Kuopio, jaak- \\ ko.mononen@uku.fi \\ 3)Pohjois-Savon Ammattikorkeakoulu, Kotikyläntie 254, 74100 Iisalmi, risto.kauppinen@pspt.fi
}

\section{Johdanto}

Lihanautoja on perinteisesti kasvatettu lämpimissä rakennuksissa rakolattiapohjaisissa ryhmäkarsinoissa tai kytkettyinä parteen. Näihin tuotantomuotoihin kuitenkin liittyy hyvinvointiongelmia. Karsinoissa eläimet pidetään usein korkeassa eläintiheydessä, mikä voi aiheuttaa eläimille stressiä ja heikentää niiden kasvua (Ingvartsen \& Andersen 1993). Parteen kytkeminen, samoin kuin liukas ja kova rakolattia vaikeuttavat makuulle asettumiseen ja ylös nousuun liittyviä liikesarjoja (Ladewig \& Borell 1988, Ruis-Heutinck ym. 2000). Lisäksi eläimillä voi esiintyä lisääntynyttä rakenteiden manipuloimista (Graf 1993).

Lihanautoja voidaan kasvattaa myös rakennuskustannuksiltaan edullisemmissa, eristämättömissä eläinsuojissa, kuten kylmäpihatoissa ja ympärivuotisissa ulkotarhoissa. Kuitenkin äärimmäisten sääolojen on pelätty vaarantavan kylmissä ympäristöissä kasvatettavien eläinten hyvinvoinnin. Toisaalta, varsinkin luonnonympäristöön perustetuissa ulkotarhoissa eläimillä on mahdollisuus käyttäytyä varsin lajityypillisesti. Lisäksi naudoilla on oltava kylmissä kasvatusympäristöissä käytössään kuivitettu makuualusta, jolla on havaittu positiivisia hyvinvointivaikutuksia naudoille (Ruis-Heutinck ym. 2000; Lowe ym. 2001).

MTT:n Pohjois-Pohjanmaan tutkimusasemalla järjestettiin tuotantokoe, jossa selvitettiin kylmien tuotantoympäristöjen soveltuvuutta lihanautojen kasvatukseen. Samassa yhteydessä tutkittiin kasvatusympäristön vaikutusta sonnien käyttäytymiseen ja hyvinvointiin.

\section{Aineisto ja menetelmät}

Tuotantokokeessa hereford-rotuisia sonneja kasvatettiin lämpimässä parsinavetassa, kylmäpihatossa ja ympärivuotisessa metsätarhassa. Navetassa 10 sonnia sijoitettiin vierekkäisiin parsiin, joiden etuosa oli kiinteää betonipohjaa ja takaosa ritilälattiaa. Kylmäpihatossa kaksi viiden sonnin ryhmää sijoitettiin vierekkäisiin karsinoihin (tilaa $6,4 \mathrm{~m}^{2} / \mathrm{eläin}$ ), joiden takaosassa sijaitsi kuivitettu makuualue ja etuosassa betonipohjainen lantakäytävä ruokintakaukaloineen. Metsätarhassa kaksi viiden eläimen ryhmää sijoitettiin vierekkäisiin aitauksiin (tilaa 0,1 ha/eläin), jotka oli aidattu nuoreen metsään. Säänsuojaksi tarhaan rakennettiin kolmiseinäinen suojakatos ( $4 \mathrm{~m}$ x $8 \mathrm{~m}$ ), jonka makuupohjaa kuivitettiin. Suojakatoksen edessä sijaitsi ruokintapaikka (4 m x $8 \mathrm{~m}$ ), jonka pohja oli betonilaattapohjainen. Suojakatos ja ruokintapaikka jaettiin kahden ryhmän käyttöön. Ruokailutilaa eläimillä oli pihatossa $0,76 \mathrm{~m} / \mathrm{eläin} \mathrm{ja} \mathrm{metsätarhassa} 1,0$ m/eläin.

Tuotantokoe alkoi marraskuussa 1999 eläinten ollessa 7 kuukauden ikäisiä ja loppui vuoden kuluttua lokakuussa. Sonneja ruokittiin vapaasti seosrehulla, jonka kuiva-aineesta $50 \%$ oli säilörehua ja loput litistettyä ohraa. Kokeen tuloksena oli, että sonnit kasvoivat yhtä hyvin kaikissa ympäristöissä, mutta kylmissä ympäristöissä eläimet kuluttivat hieman enemmän rehua kuin navetassa (Huuskonen ym. 2002). Tulos voidaan tulkita siten, että eläinten tuotannon perusteella kylmässä kasvatus ei vaaranna lihanautojen hyvinvointia, jos eläimillä on käytössään asianmukaiset tilat ja niitä hoidetaan huolellisesti.

Sonnien käyttäytymistä tutkittiin heinä-, elo- ja syyskuussa. Käyttäytymistutkimuksen alkaessa sonnit olivat keskimäärin 15,5 kuukauden ikäisiä ja $655 \mathrm{~kg}$ :n painoisia. Sonneja tarkkailtiin suoralla seurannalla noin kuuden tunnin jaksoissa. Tarkkailua tehtiin jokaisena kuukautena yhteensä 24 tunnin ajan, paitsi metsätarhassa vain vuorokauden valoisana aikana. Navetassa ja pihatossa käytettiin keinovaloa vuorokauden pimeänä aikana. Sonnien käyttäytymistoiminnot kirjattiin hetkellisellä seurannalla viiden minuutin välein. Metsätarhassa sonnien sijainti tarhassa havainnoitiin viiden minuutin välein ja eläinten ryhmäkäyttäytyminen kymmenen minuutin välein. Eläimet määriteltiin kuuluvaksi ryhmään, kun niiden välinen etäisyys oli enintään viisi metriä. Ryhmäkäyttäytymisen tutkimiseksi määritettiin ryhmäpreferenssiindeksi (Gattermann 1990). Sontimista havainnoitiin jatkuvalla seurannalla.

Tilastollisiin tarkasteluihin aineistoa otettiin mukaan lyhyimmän tarkkailun (syyskuu metsätarhassa) mukaan, joten mukana ovat havainnot vain kello 6:00 - 21:00 väliseltä ajalta. Sonneilla havaittiin kymmeniä erilaisia käyttäytymistoimintoja, jotka luokiteltiin neljään pääkäyttäytymisluokkaan: lepoon (makaaminen joutilaana ja nukkuminen), syömiskäyttäytymiseen (syöminen ja juominen), märehtimiseen 
ja ns. muuhun aktiivisuuteen (seisominen joutilaana, liikkuminen, ympäristön tarkkailu ja tutkiskelu, turkin hoito ja sosiaalinen käyttäytyminen). Tilastollinen testaus tehtiin SPSS 11.5 -ohjelmistolla. Pääkäyttäytymisluokat testattiin toistomittausten varianssianalyysillä (GLM). Muut muuttujat testattiin KruskallWallis -testillä tai Mann-Whitney -testillä. Jos parametristen testien ehdot täyttyivät, käytettiin yksisuuntaista varianssianalyysiä tai riippumattomien ryhmien T-testiä.

\section{Tulokset ja tulosten tarkastelu}

Sonnien vuorokausirytmissä (tulokset heinäkuulta, jolloin tarkkailua koko vuorokauden ajalta) havaittiin sekä yhtäläisyyksiä että eroja eri kasvatusympäristöissä. Kaikissa ympäristöissä sonnit viettivät yön lepäillen ja märehtien. Aamulla sonnit ruokittiin, jolloin syömiseen kulutettu aika lisääntyi. Iltapäivän sonnit viettivät enimmäkseen lepäilemällä ja märehtimällä. Pihatossa ja metsätarhassa sonneille lisättiin rehua myös illalla, jolloin syömiseen kulutettu aika lisääntyi. Kaikissa ympäristöissä sonnit olivat aktiivisimmillaan illalla, jolloin tarhassa ja pihatossa esiintyi runsaasti sosiaalista käyttäytymistä. Aktiivisuuspiikki ajoittui eri aikaan eri ympäristöissä, metsätarhassa myöhäisimmäksi ja navetassa aikaisimmaksi.

Kuvassa 1 on esitetty sonnien klo 6:00 - 21:00 välinen ajankäyttö eri kuukausina. Navetassa eri toimintojen osuudet ajankäytöstä säilyivät tasaisimpina eri kuukausina, mikä voi johtua navetan tasaisemmista ympäristöoloista. Kaikissa ympäristöissä voidaan kuitenkin havaita suuntaus ns. muun aktiivisuuden lisääntymiseen syksyä kohden mentäessä. Vastaavasti levon ja/tai märehtimisen osuus ajankäytöstä on vähentynyt. Syömiskäyttäytymiseen kulutetussa ajassa ei eri kuukausina tapahdu suuria muutoksia. Metsätarhassa sonnit märehtivät varsinkin heinäkuussa enemmän kuin muissa ympäristöissä, mutta ero tasoittuu syksyä kohden mentäessä. Muutokset ajankäytössä eri kuukausina voivat johtua eläinten vuorokausirytmin siirtymisestä syksyä kohden mentäessä. Päivän lyhetessä eläimet ovat voineet käyttää valoisan ajan tarkemmin hyödykseen olemalla aktiivisempia päiväsaikaan, jolloin osa lepäilystä ja märehtimisestä on siirtynyt yöajalle.

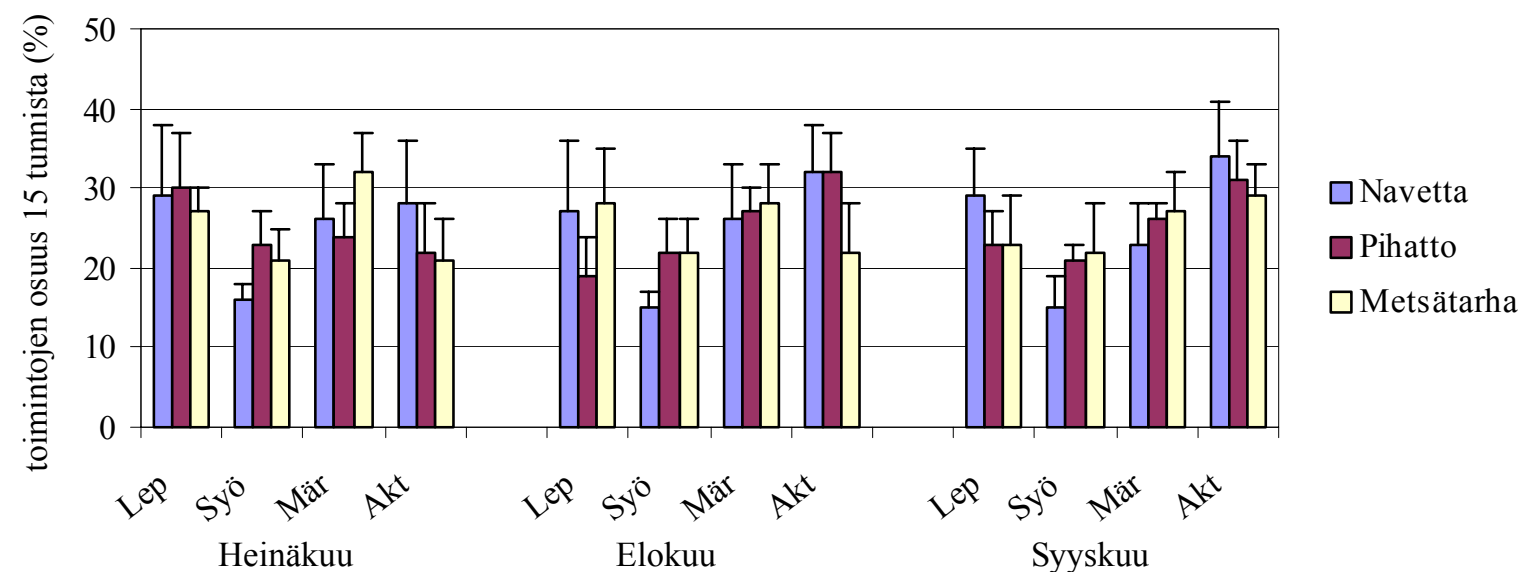

Kuva 1. Sonnien käyttäytymistoiminnot (K) eri kasvatusympäristöissä (Y) heinä-, elo- ja syyskuussa (A). Ajankäytön jakautuminen lepoon, syömiskäyttäytymiseen, märehtimiseen ja muuhun aktiivisuuteen on ilmoitettu prosentteina klo 6:00 - 21:00 väliseltä ajalta. GLM: K, p<0,001; K x Y, p<0,001; K x A, p<0,001 ja K x Y x A, p<0,01.

Taulukossa 1 on tarkasteltu sonnien ajankäyttöä kolmen tarkkailukuukauden keskiarvona. Levon kokonaismäärässä ei havaittu tilastollista eroa eri ympäristöissä, mutta lepäämällä vietetty aika jakautui eri asentoihin hieman eri tavoin eri ympäristöissä. Kuitenkin suurimman osan lepoajastaan sonnit makasivat pää ylhäällä. Naudan maatessa kerällä, kyljellään tai kaula ja pää ojennettuina eteen maahan eläimen kaula rentoutuu ja eläin voi nukkua syvää unta (Ruckebusch ym. 1974). Kun nämä varsinaiset nukkumisasennot yhdistettiin, niitä havaittiin vähemmän navetassa kuin muissa ympäristöissä. Siten sonnit saattoivat päiväsaikaan nukkua vähemmän syvää unta navetassa kuin muissa ympäristöissä, mikä voi olla seurausta tarkkailijan häiritsevästä läsnäolosta.

Kaikissa ympäristöissä sonnit käyttivät aikaa annetun rehun syömiseen yhtä paljon. Pihatossa ja tarhassa eläimillä oli käytössään 10 eläintä kohden yksi juomakuppi, johon vesi virtasi hitaasti. Tämän vuoksi etenkin pihatossa juomiseen kului aikaa sonnien tungeksiessa juomakupilla. Metsätarhassa sonnit etsivät lisäravintoa metsäalueelta. Rakenteiden manipulointia (nuolemista, puremista, puunkuoren naker- 
tamista tarhassa) esiintyi eniten tarhassa ja vähiten pihatossa. Tarhassa manipulointi oli hieman erilaista kuin muissa ympäristöissä; eläimet repivät puiden kuorta tai kaarnaa ja söivät irronneen aineksen. Kaikkiaan märehtimistä esiintyi hieman enemmän metsätarhassa kuin muissa ympäristöissä, mikä voi johtua eläinten tarha-alueelta hankkimasta karkeammasta luonnonravinnosta, joka on voinut vaatia perusteellisemman märehtimiskäsittelyn. Pihatossa lisääntynyt seisaallaan märehtiminen voi olla seurausta karsinan toisten eläinten häiritsevästä liikehdinnästä.

Taulukko 1. Sonnien käyttäytymistoiminnot eri ympäristöissä heinä-, elo, ja syyskuun keskiarvona kello 6:00 21:00 väliseltä ajalta (keskiarvo \pm keskihajonta). Koska tietyt käyttäytymistoiminnot (märehtiminen ja muutamat ns. muun aktiivisuuden toiminnot) saattoivat esiintyä samanaikaisesti, luokat eivät summaudu sataan.

\begin{tabular}{|c|c|c|c|c|}
\hline Käyttäytymistoiminto & Navetta & Pihatto & Metsätarha & Merkitsevyys \\
\hline Lepo yht. & $28,3 \pm 6,8$ & $24,1 \pm 3,3$ & $25,8 \pm 4,1$ & $\mathrm{a}$ \\
\hline makaa joutilaana pää ylhäällä & $24,6 \pm 6,7^{\mathrm{Q}}$ & $17,5 \pm 2,8^{\mathrm{R}}$ & $18,4 \pm 4,5^{\mathrm{R}}$ & $* *^{\mathrm{a}}$ \\
\hline nukkuu kerällä & $1,3 \pm 1,0^{\mathrm{Q}}$ & $2,2 \pm 1,4^{\mathrm{QR}}$ & $2,9 \pm 1,9^{\mathrm{R}}$ & $\mathrm{o}^{\mathrm{c}}$ \\
\hline nukkuu kyljellään & $1,4 \pm 1,5^{\mathrm{Q}}$ & $1,6 \pm 1,1^{\mathrm{QR}}$ & $3,1 \pm 1,7^{\mathrm{R}}$ & $*^{\mathrm{a}}$ \\
\hline nukkuu pää ojennettuna eteen maahan & $1,0 \pm 0,7^{\mathrm{Q}}$ & $2,7 \pm 1,5^{\mathrm{R}}$ & $1,3 \pm 1,2^{Q}$ & $* *^{\mathrm{a}}$ \\
\hline nukkuu yht. & $3,8 \pm 1,8^{Q}$ & $6,6 \pm 2,0^{\mathrm{R}}$ & $7,3 \pm 2,2^{\mathrm{R}}$ & $* * \mathrm{c}$ \\
\hline Syömiskäyttäytyminen yht. & $15,4 \pm 2,3^{\mathrm{Q}}$ & $21,8 \pm 2,6^{\mathrm{R}}$ & $21,5 \pm 3,5^{\mathrm{R}}$ & $* * *^{\mathrm{a}}$ \\
\hline syö rehua & $14,1 \pm 2,3$ & $15,1 \pm 1,7$ & $13,4 \pm 1,0$ & $\mathrm{a}$ \\
\hline syö kuiviketta & - & $0,48 \pm 0,32^{Q}$ & $0,04 \pm 0,12^{\mathrm{R}}$ & $* *^{\mathrm{d}}$ \\
\hline laiduntaa metsässä & - & - & $5,2 \pm 3,0$ & \\
\hline juo & $0,41 \pm 0,30^{\mathrm{Q}}$ & $5,8 \pm 1,6^{\mathrm{R}}$ & $1,7 \pm 0,7^{\mathrm{S}}$ & $* * * \mathrm{c}$ \\
\hline manipuloi rakenteita / puun kuorta & $0,80 \pm 0,31^{\mathrm{QR}}$ & $0,39 \pm 0,36^{\mathrm{Q}}$ & $1,2 \pm 0,5^{\mathrm{R}}$ & $* * *^{\mathrm{a}}$ \\
\hline Märehtiminen yht. & $25,0 \pm 4,8$ & $25,7 \pm 2,1$ & $29,0 \pm 3,3$ & $*^{\mathrm{a}}$ \\
\hline märehtii makuulla & $21,7 \pm 4,0^{\mathrm{QR}}$ & $17,8 \pm 3,2^{\mathrm{Q}}$ & $25,0 \pm 3,4^{\mathrm{R}}$ & $* * *^{\mathrm{a}}$ \\
\hline märehtii seisaallaan & $3,3 \pm 2,1^{\mathrm{Q}}$ & $7,9 \pm 2,5^{\mathrm{R}}$ & $4,0 \pm 1,1^{\mathrm{Q}}$ & $* * * \mathrm{c}$ \\
\hline Muu aktiivisuus yht. & $31,3 \pm 5,4^{\mathrm{Q}}$ & $28,6 \pm 4,1^{\mathrm{QR}}$ & $24,0 \pm 3,9^{\mathrm{R}}$ & $* *^{\mathrm{a}}$ \\
\hline seisoo joutilaana & $30,3 \pm 5,1^{\mathrm{Q}}$ & $14,8 \pm 2,6^{\mathrm{R}}$ & $7,1 \pm 2,1^{\mathrm{S}}$ & $* * *^{\mathrm{c}}$ \\
\hline käyskentelee, kävelee & - & $0,46 \pm 0,32^{\mathrm{Q}}$ & $2,3 \pm 0,8^{\mathrm{R}}$ & $* * * \mathrm{~b}$ \\
\hline tarkkailee, tutkiskelee ympäristöä & $0,28 \pm 0,22^{\mathrm{Q}}$ & $1,3 \pm 0,4^{\mathrm{R}}$ & $2,6 \pm 1,1^{\mathrm{R}}$ & $* * * \mathrm{c}$ \\
\hline hoitaa turkkiaan & $0,62 \pm 0,51^{\mathrm{Q}}$ & $0,83 \pm 0,41^{\mathrm{Q}}$ & $3,4 \pm 1,4^{\mathrm{R}}$ & $* * * \mathrm{c}$ \\
\hline nuolee toista eläintä, on nuoltavana & $0,07 \pm 0,10^{\mathrm{Q}}$ & $0,96 \pm 0,65^{\mathrm{R}}$ & $0,66 \pm 0,51^{\mathrm{R}}$ & $* * *^{\mathrm{c}}$ \\
\hline puskee toista eläintä, on puskettavana & - & $0,78 \pm 0,45$ & $0,68 \pm 0,31$ & $\mathrm{~b}$ \\
\hline seurustelee toisen eläimen kanssa & $0,00 \pm 0,00^{\mathrm{Q}}$ & $5,6 \pm 1,1^{\mathrm{R}}$ & $6,8 \pm 1,4^{\mathrm{R}}$ & $* * * \mathrm{c}$ \\
\hline tarkkailee, tutkii naapurikarsinan eläintä & - & $3,9 \pm 2,1^{Q}$ & $0,42 \pm 0,49^{\mathrm{R}}$ & $* * * \mathrm{~d}$ \\
\hline
\end{tabular}

Tilastollinen merkitsevyys: eri yläindeksit ${ }^{\text {QRS }}$ osoittavat koeryhmien välistä tilastollisesti merkitsevää eroa. Tilastolliset testit: ${ }^{\mathrm{a}}$ yksisuuntainen varianssianalyysi, ${ }^{\mathrm{b}}$ riippumattomien ryhmien t-testi, ${ }^{\mathrm{c}}$ Kruskal-Wallis -testi, ${ }^{\mathrm{d}}$ MannWhitney -testi.

Navetassa sonnien ns. muu aktiivisuus koostui miltei yksinomaan joutilaana seisomisesta. Parressa eläinten sosiaalinen käyttäytyminen oli hyvin vähäistä ja rajoittunutta, ne korkeintaan pystyivät haistelemaan tai nuolemaan vieressä seisovaa eläintä. Pihatossa ja tarhassa sonnien sosiaalinen käyttäytyminen oli melko samanlaista: toisen eläimen kanssa seurustelua ja toisen eläimen nuolemista sekä puskemista oli lähes yhtä paljon. Pihatossa ja tarhassa eläimet tutkivat ja tarkkailivat ympäristöään enemmän kuin navetassa. Pihatossa eläimet lisäksi kurkottelivat karsinoita erottavan aidan raoista nuuskien ja tarkkaillen naapurikarsinan eläimiä. Tarhassa sonnit käyskentelivät metsäalueella, ja hoitivat turkkiaan muita ympäristöjä enemmän.

Naudoilla toiseen eläimeen kohdistuvan puskemisen on havaittu lisääntyvän eläintiheyden kasvaessa (Kondo ym. 1989). Tämän on esitetty johtuvan yksilötilan loukkausten lisääntymisestä sekä rajallisiin resursseihin kohdistuvasta kilpailusta (Wierenga 1983). Tässä tutkimuksessa metsätarhassa ja pihatossa esiintyi yhtä paljon puskemiskäyttäytymistä. Tämä voi johtua melko tilavasta pihattokarsinasta, jossa tilaa eläintä kohden oli enemmän (6,4 m²/eläin) kuin eläinsuojelusäädöksissä tämän kokoisille lihanaudoille kiinteällä pohjalla suositellaan (4,0 m²/eläin) (Maa- ja metsätalousministeriö 1997). Karsinassa eläimillä oli ilmeisestikin jossain määrin mahdollisuuksia väistää toisiaan. Toisaalta, molemmissa ympäristöissä 
eläimet myös hakeutuivat toistensa seuraan kamppailemaan puskemalla. Leikkitappeluita, jotka sisälsivät nautojen leikille tyypillisiä piirteitä, esiintyi etenkin iltahämärissä.

Metsätarhan sonnien ryhmäpreferenssi (klo 6:00 - 21:00 väliseltä ajalta) oli heinäkuussa 73 \%, elokuussa $63 \%$ ja syyskuussa $51 \%$. Siten eläimet viettävät suuren osan ajastaan toisten eläinten läheisyydessä, vaikka tilaa olisi ollut runsaasti myös erillään oloon.

Navetassa sonneilla havaittiin makuulle asettumisessa vaikeuksia, jotka ilmenivat pitkittyneinä ja keskeytyneinä makuulle asettumisen yrityksinä. Makuulle asettumisen vaikeuksia esiintyy yleisesti rakolattioilla kasvatettavilla naudoilla (Ruis-Heutinck ym. 2000). Vaikeuksien syyksi on esitetty kovaa ja liukasta lattiaa, jolloin eläin ei saa pitävää otetta sorkalleen, mistä seuraa eläimen liikkeiden muuttuminen epävarmoiksi. Myös tässä tutkimuksessa parren takaosan ritilälattia oli liukas, jonka lisäksi myös tilan puute korkeasta ruokintapöydän reunasta johtuen ja eläimen kytkeminen ovat osaltaan vaikeuttaneet sonnien liikkeitä.

Metsätarhassa sonnit oleskelivat kaikilla aitauksen alueilla. Koko kesän keskiarvona kello 6:00 $21: 00$ väliseltä ajalta sonnit oleskelivat ajastaan $23,8 \%$ suojarakennuksessa, $19,8 \%$ betonilaattapohjaisella ruokinta-alueella suojarakennuksen edessä, $2,4 \%$ suojarakennusta ja ruokintapaikkaa ympäröivällä pihaalueella ja 24,4 \% metsäisen alueen etuosassa ja 29,6 \% metsäisen alueen kauimmaisessa osassa. Sonnit käyttivät sekä suojarakennuksen makuupaikkaa että tarhan metsäaluetta makaamiseen. Sonnasta puolet $(51,5 \%)$ kerääntyi suojarakennukseen ja ruokintapaikalle, joista lanta pystyttiin poistamaan.

\section{Johtopäätökset}

Tutkimus osoittaa, että sonneilla on metsätarhassa ja pihatossa parsinavettaa paremmat mahdollisuudet monimuotoisempaan ja lajinmukaiseen käyttäytymiseen. Tarjottaessa sonneille tilava ja vaihteleva ympäristö, eläimet käyttävät sen hyväkseen käyttäytymällä monin eri tavoin. Parteen kytkeminen rajoittaa sonnien elämää suuresti, minkä vuoksi eläimet pystyvät toteuttamaan vain osaa käyttäytymistarpeistaan. Lisäksi navetassa vaikeudet makuulle asettumisessa viittaavat sonnien vaikeuksiin sopeutua ympäristöönsä ja eläinten heikentyneeseen hyvinvointiin. Tässä tutkimuksessa tutkittiin vain eläinten käyttäytymistä, ja kattavampaan hyvinvoinnin arviointiin päästäisiinkin mittaamalla myös muita, kuten terveyteen ja fysiologiaan liittyviä hyvinvointiparametrejä.

\section{Kirjallisuus}

Gattermann, R. 1990. Verhaltensbiologisches praktikum. VEB Gustav Fisher Verlag, Jena.

Graf, B. 1993. Abnormal oral behaviours in fattening bulls: incidence, causation and implications. Julkaisussa: Nichelmann, M., Wierenga, H.K. \& Braun, S. (toim.) Proceedings of the international congress on applied ethology, Berlin 1993: 47-52.

Huuskonen, A., Joki-Tokola, E. \& Huttu, S. 2001. Lihanautojen kasvatus kylmissä tuotantoympäristöissä. Julkaisussa: Maataloustieteen päivät. MKL:n julkaisuja nro 977: 36-39.

Ingvartsen, K.L. \& Andersen, H.R. 1993. Space allowance and type of housing for growing cattle. A review of performance and possible relation to neuroendocrine function. Acta Agric. Scand. Sect. A, Animal Sci. 43: 65-80.

Kondo, S., Sekine, J., Okubo, M. \& Asahida, Y. 1989: The effect of group size and space allowance on the agonistic and spacing behavior of cattle. Applied Animal Behaviour Science 24: 127-135.

Ladewig, J. \& Borell, E.V. 1988. Ethological methods alone are not sufficient to measure the impact of environment on animal health and animal well-being. Julkaisussa : Unshelm, J., Putten, G. van, Zeeb, K. \& Ekesbo, I. (toim.) Proceedings of the International Congress on Applied Ethology in Farm Animals, Skara, 1988: 95-102.

Lowe, D.E., Steen, R.W.J. \& Beattie, V.E. 2001. Preferences of housed finishing beef cattle for different floor types. Animal Welfare 10: 395-404.

Maa- ja metsätalousministeriö. 1997. Nautojen pidolle asetettavat eläinsuojeluvaatimukset. Päätös nro 14/EEO/1997. Maa- ja metsätalousministeriö.

Ruckebusch, Y., Dougherty, R.W. \& Cook, H.M. 1974. Jaw movements and rumen motility as criteria for measurement of deep sleep in cattle. Am J Vet Res 10: 1309-1312.

Ruis-Heutinck, L.F.M., Smits, M.J.C., Smits, A.C. \& Heeres, J.J. 2000. Effects of floor type and floor area on behaviour and carpal joint lesions in beef bulls. Julkaisussa: Blokhuis, H.J., Ekkel, E.D., Wechsler, B. (toim.) Improving health and welfare in animal production. Proceedings of sessions of the EAAP commission on animal management and health, the Hague, the Netherlands, 21-24 August 2000: 29-36. Wageningen Pers. Wageningen, Netherlands

Wierenga, H.K. 1983. The influence of the space for walking and lying in a cubicle system on the behaviour of dairy cattle. Julkaisussa: Baxter, S.H., Baxter, M.R. \& MacCormack, J.A.D. (toim.) Farm Animal Housing and Welfare. CEC Seminar: 171-180. Martinus Nijhoff, Boston. 